\title{
Efficacy of Achyranthes aspera (L.) as a Molluscicidal Bait Formulation against Fresh Water Snail Biomphalaria pfeifferi
}

\author{
Belayhun Mandefro $\mathbb{D}^{1,2}$ Seid Tiku Mereta, ${ }^{1}$ and Argaw Ambelu $\mathbb{D}^{1}$ \\ ${ }^{1}$ Department of Environmental Health Science and Technology, Faculty of Public Health, Jimma University, \\ P.O. Box 378, Jimma, Ethiopia \\ ${ }^{2}$ Department of Biology, College of Natural and Computational Sciences, Dilla University, P.O. Box 419, Dilla, Ethiopia
}

Correspondence should be addressed to Belayhun Mandefro; belayhunmandefro@gmail.com

Received 11 April 2018; Accepted 3 June 2018; Published 27 June 2018

Academic Editor: Samra Bashir

Copyright (C) 2018 Belayhun Mandefro et al. This is an open access article distributed under the Creative Commons Attribution License, which permits unrestricted use, distribution, and reproduction in any medium, provided the original work is properly cited.

\begin{abstract}
Molluscicidal plant products have interesting attributes of environmental friendliness and accessibility to local communities. Their bait formulations are more economical and target specific as they are applied only to the snail-infested sections of the water habitat. Their active ingestion by target snails could also increase gastric concentrations and enhance effectiveness. This study aimed to evaluate the comparative effectiveness of Achyranthes aspera (A. aspera) leaf hydroethanolic extract in bait and immersion applications. Serial dilutions of the extract in water for immersion, and in snail food pellets for bait test, were set. Adult Biomphalaria pfeifferi snails exposed to the bioassays for 24 hours and data were analyzed using probit model. The plant showed molluscicidal activity in both methods. The respective $\mathrm{LC}_{50}$ and $\mathrm{LC}_{90}$ doses were 20.37 and $46.84 \mathrm{ppm}$ in the immersion and 3.10 and 11.08 $\mathrm{ppm}$ in the bait. The more efficient bait method reduced the $\mathrm{LC}_{50}$ by 6.57 and the $\mathrm{LC}_{90}$ by 4.23 times. This finding provides a strong foundation for the molluscicidal potential of $A$. aspera. It is applicable and possibly more effective if formulated into those commercially available snail food pellets or flakes. However, selection and optimization of suitable baits is a crucial step for maximum output.
\end{abstract}

\section{Background}

Schistosomiasis control can be more successful when chemotherapy and snail control activities are integrated $[1,2]$. Recently, molluscicidal plants are drawing more and more attention for their environmental friendliness, accessibility, and cost effectiveness. They are especially suitable for community based snail control activities in places where schistosomiasis transmission is more focal [3]. So far, several molluscicidal plants have been screened worldwide. Carica papaya (C. papaya), Terminalia catappa (T. catappa) [4] and Solanum species [5] are just some of them. Glinus lotoides (G. lotoides) [6], and Pueraria peduncularis ( $P$. peduncularis ) [7] are also among the recently discovered ones.

The relatively low efficacy of many molluscicidal plants as compared to niclosamide is a hindrance to their practical applicability [8]. Parallel to the search for noble molluscicides of higher efficacy and safety, adoption of efficient application mechanisms could play a decisive role in enhancing their effectiveness. In principle, such molluscicides should be applied in dose as low as possible for environmental, natural resource conservation and economic reasons $[9,10]$. In the usual immersion method, the molluscicide is added to the water habitat $[11,12]$ and is needed in large amount to titrate the entire water body. Alternatively, molluscicidal baits are formulated irrespective of the water volume and are applied only to the snail-infested sections requiring only a very small amount of active ingredients. Baits use as carriers of the molluscicide and attractants which increase palatability of the substance by target snails [13-15]. Such baits have been practiced against freshwater snail Lymnaea acuminata by some researchers [16-18].

Achyranthes aspera (A. aspera) is a perineal herb in the family Amaranthaceae. The plant grows in many parts of Ethiopia on roadsides, on wastelands, near hedges, and under 
eucalyptus tree plantations. It is a known medicinal plant in Ethiopian folklore used for placental retention, postpartum bleeding, skin eruptions, and wound dressing $[19,20]$. This study is aimed to evaluate the comparative efficacy of $A$. aspera leaf hydroethanolic extract against Biomphalaria pfeifferi (B. pfeifferi) snails in molluscicidal bait and immersion applications, in the laboratory condition.

\section{Material and Methods}

2.1. Plant Material Collection and Processing. The plant was selected for this study based on the researchers' previous screening tests. Mature green leaves were collected in October 2016 from a natural habitat located at $9^{\circ} 43^{\prime} 45.59^{\prime \prime} \mathrm{N}$, $39^{\circ} 73^{\prime} 2.71^{\prime \prime} \mathrm{E}$, central Ethiopia. It was dried in the shade and ground to fine powder of $200 \mu \mathrm{m}$ mesh size as in Adenusi and Odaibo [21]. It was stored in plastic bags in the laboratory of Environmental Health Science and Technology, Jimma University, Ethiopia. Experts in Addis Ababa University Herbarium have identified and authenticated the plant species. Voucher specimen with specimen number: M.B.1 is kept in the herbarium.

2.2. Extract Preparation. Considering the relative polarity of the presumed molluscicidal phytochemicals such as saponins $[1,22]$, hydroethanol is selected as an efficient extraction solvent. In addition, hydroethanol renders more extract yield than absolute ethanol [22, 23]. Ethanol is also safer and less toxic than methanol, acetone, and other organic solvents. Extraction was done with slight modification of the procedure in Ndamukong and colleagues [24]. Exactly $100 \mathrm{~g}$ plant powder was rinsed in $1000 \mathrm{ml}$ of $80 \%$ ethanol in a flat-bottomed airtight flask and shook on an orbital shaker for 24 hours at $125 \mathrm{rpm}$ at room temperature. After filtration with Whatman filter paper $(110 \mathrm{~mm}$ thickness CAT No. 1540 110), the filtrate evaporated from a wide mouth beaker placed in a water bath at $40^{\circ} \mathrm{C}$. The resulting blueblack sticky amorphous matrix was stored in a dry clean container.

2.3. Phytochemical Analysis. Qualitative phytochemical screening tests were done on the extract based on standard procedures described in Akinyemi et al. [25], Sasidharan et al. [26], and Mungenge et al. [27]. Reducing sugars were identified by Fehling's test. Biuret test was used for proteins, froth test for saponins, $5 \%$ ferric chloride for total phenolics, and $10 \%$ ferric chloride and gelatin test for tannins. Alkaline test and concentrated sulphuric acid in ammonia were used for flavonoid test. In addition, Wagner's test for alkaloids, Salkowski reaction for terpenoids, and Liebermann-Burchard test for steroids were applied.

2.4. Snail Food Preparation. We used lettuce (Lactuca sativa) leaves for snail food. About $2 \mathrm{~kg}$ of young leaves, separated from the stems and midribs, was partially cooked in boiling tap water for 2 minutes. The par-boiled leaves were dried under the shade on a clean plastic sheet. It was ground to a fine powder of $250 \mu \mathrm{m}$ mesh size and stored in airtight plastic bags.
2.5. Snail Collection and Maintenance. We collected adult snails of $B$. pfeifferi from stream habitats located at $7^{\circ} 41^{\prime} 15.39^{\prime \prime}$ N, $36^{\circ} 50^{\prime} 52.32^{\prime \prime}$ E, in Jimma Town Public Prison agricultural field, southwestern Ethiopia. Snails were transported to the laboratory in clean plastic buckets half-filled with water from the streams. We acclimatized them in the laboratory for one week in 3 clean large plastic buckets filled with $10 \mathrm{l}$ aged water, each containing 200 snails, at room temperature under $12 \mathrm{~h}$ light and $12 \mathrm{~h}$ dark photoperiods. Snails were fed with the previously prepared lettuce leaf powder by spreading about 0.25 g powder into each bucket in every 24 hours and water was replaced in every 3 days. The snails were ethically handled throughout the experiment according to the principles and guidelines of animal welfare in scientific researches [28, 29]. They were not subjected to cercaria shedding before or after the experiment. However, an independent and contemporary study indicated a $28.5 \%$ snail infection rate (Bedewi et al., unpublished).

2.6. Molluscicidal Test Assay in Immersion Method. The molluscicidal test assay was established based on standard procedures adopted for immersion type of test [30]. Stock solution of $1000 \mathrm{ppm}$ was prepared by dissolving $0.5 \mathrm{~g}$ plant extract in $500 \mathrm{ml}$ aged water. From this, $100 \mathrm{ml}$ dilutions of $3.13,6.25,12.5,25,50$, and $100 \mathrm{ppm}$ were prepared in clean beakers. Ten adult $B$. pfeifferi snails, shell diameter 9.5$10.6 \mathrm{~mm}$, were exposed to each dilution without food for 24 hours at room temperature. The test was performed in three replicates. Positive control was prepared from $1.5 \mathrm{ppm}$ niclosamide and negative control from only aged water. After 24 hours, the snails in their respective groups were removed from the solutions, washed with aged water in a childcare manner, and transferred to new beakers with aged water and food for another 24 hours. Finally, dead and alive snails were counted through careful inspection. Snails were considered dead if they lose sense when the foot is pocked with needle or if they remain retracted in to the shell or else the foot is discolored $[6,30]$.

2.7. Molluscicidal Test Assay in Bait Method. Molluscicidal baits in the form of pellets were prepared based on the methods in Laskowski and Hopkin [31] and Srivastava et al. [18]. Different masses of the extract, 0.024, 0.047, 0.094, 0.188, $0.375,0.750$, and $1.500 \mathrm{mg}$, dissolve in $10 \mathrm{ml}$ distilled water. To each of these solutions, a $5 \mathrm{~g}$ lettuce powder was added to make a $15 \mathrm{~g}$ homogenized pellet. Hence, the corresponding concentrations of the extract in the pellets were 1.57, 3.13, $6.25,12.5,25$, and $50 \mathrm{ppm}$. Each pellet was evenly pasted on the inside base of a clean Petri dish ( $9.5 \mathrm{~mm}$ diameter) by pressing with smooth flat wooden applicator. Ten adult $B$. pfeifferi snails of $9.5-10.8 \mathrm{~mm}$ shell diameter were released in to each Petri dish for 24 hours. Wet cotton was put over the snails to maintain wet environment as adapted from Laskowski and Hopkin [31]. The test was carried out in four replicates with positive control made from pellet consisting of 1.5 ppm niclosamide (Bayer and Pro-Serv. Inc. Germany) and negative control pellet from only lettuce powder. After 24 hours, the snails from each bait were collected, carefully washed, and maintained in clean beakers with aged water and 
TABLE 1: Results of phytochemical screening tests on A. aspera leaf hydroethanolic extract. Here their relative abundances are expressed as +++ for more abundant, ++ for moderately abundant, + for trace, and - for none.

\begin{tabular}{lcc}
\hline Phytoconstituents & Screening tests & Observation \\
\hline reducing sugars & Fehling's test & + \\
proteins & Biuret's test & froth/foam test \\
saponins & $5 \% \mathrm{FeCl}_{3}$ test & + \\
total phenolics & $10 \% \mathrm{FeCl}_{3}$ test \\
tannins & gelatin test \\
& reaction with $\mathrm{H}_{2} \mathrm{SO}_{4}$ in ammonia \\
flavonoids & alkaline test $(\mathrm{KOH})$ \\
& Wagner's test \\
alkaloids & Salkowski reaction \\
terpenoids & Liebermann-Burchard reaction \\
steroids & + \\
\hline
\end{tabular}

TABLE 2: Mortality data showing the total number of exposed and dead B. pfeifferi snails in each concentration of $A$. aspera leaf hydroethanolic extract during immersion and bait tests.

\begin{tabular}{|c|c|c|c|c|c|}
\hline \multicolumn{3}{|c|}{ Immersion test } & \multicolumn{3}{|c|}{ Bait test } \\
\hline concentration (ppm) & exposed & dead & concentration (ppm) & exposed & dead \\
\hline 0.00 & 30 & 0 & 0.00 & 40 & 2 \\
\hline 3.13 & 30 & 0 & 1.57 & 40 & 7 \\
\hline 6.25 & 30 & 2 & 3.13 & 40 & 23 \\
\hline 12.50 & 30 & 7 & 6.25 & 40 & 32 \\
\hline 25.00 & 30 & 15 & 12.50 & 40 & 37 \\
\hline 50.00 & 30 & 29 & 25.00 & 40 & 38 \\
\hline 100.00 & 30 & 30 & 50.00 & 40 & 40 \\
\hline
\end{tabular}

food for another 24 hours. Finally, live and dead snails in each treatment group were counted with careful inspection. Snail death was confirmed by loss of sense when pocked with a needle or by discolored mantle.

2.8. Data Analysis. The mortality data were analyzed using probit regression model in IBM SPSS program version 23 to determine the $\mathrm{LC}_{50}$ and $\mathrm{LC}_{90}$ doses with their respective upper and lower limits [32, 33]. These are the principal endpoints considered as a measure of molluscicidal efficacy. In addition, the nature of correlations existing between concentrations and mortality rates were assessed from the slope function.

\section{Results}

3.1. Phytochemical Analysis of the Leaf Hydroethanolic Extract. The phytochemical screening test results, (Table 1) revealed that the extract consists of a number of bioactive secondary metabolites. Saponins and flavonoids were found in relative abundance but tannins and proteins were not detected in this particular test.

3.2. Molluscicidal Activity. In the immersion test, snails exhibited irritative behavior and try to escape from the solutions by crawling up beyond the water level. They produced more mucus. Bleeding was observed later in the course of the experiment. They started to show signs of paralysis or death after the first six hours of exposure. When snails were exposed to the molluscicidal baits, they come out of their shells and move about over the pellet in the first hour. Then they gradually became inactive, reluctant to move, and started retracting to their shells. During the rehabilitation period, survivors come out of their shells and resumed activity.

Snail mortalities in the two tests are presented in Table 2. The record clearly showed that mortality rates increase with increasing concentrations of the extract.

The resulting probit analysis (Table 3 ) shows that the calculated $\chi^{2}$ values are less than the tabular values. This indicates that the data are qualified for Pearson's goodness of fit. In addition, the positive slope indicates positive correlations between mortality rates and concentrations.

\section{Discussion}

The findings of this study revealed $A$. aspera has a concentration-dependent molluscicidal effect against adult B. pfeifferi snails in both immersion and bait applications. However, the two methods exhibited different efficacies. The $\mathrm{LC}_{50}$ concentration in the bait is smaller than that in the immersion test (Table 3). This indicates the plant is more efficacious when applied as molluscicidal bait than its immersion form. 
TABLE 3: The $\mathrm{LC}_{50}$ and $\mathrm{LC}_{90}$ doses (with confidence limits) of $A$. aspera leaf hydroethanolic extract against $B$. pfeifferi snails in immersion and bait tests.

\begin{tabular}{lccr}
\hline Test method & Effective doses & Confidence limits & $\chi^{2}(95 \% \mathrm{CL})$ \\
\hline \multirow{2}{*}{ Immersion } & $\mathrm{LC}_{50}=20.37$ & $16.97-24.57$ & 4.158 \\
& $\mathrm{LC}_{90}=46.84$ & $36.86-67.12$ & 3.544 \\
\multirow{2}{*}{ Bait } & $\mathrm{LC}_{50}=3.10$ & $1.29-5.16$ & 4.760 \\
& $\mathrm{LC}_{90}=11.08$ & $7.04-17.00$ & 2.319 \\
\hline
\end{tabular}

Previous studies have shown that the aqueous extract of $A$. aspera is effective against $B$. pfeifferi snails with 72.4 ppm $\mathrm{LC}_{50}$ and 96.5 ppm $\mathrm{LC}_{90}$ [34]. In the current study, the hydroethanolic extract exhibited a higher potency (20.37 ppm $\mathrm{LC}_{50}$ and $46.84 \mathrm{ppm} \mathrm{LC}_{90}$ ) by the same immersion technique. Similar to many other studies [35], the alcoholic extract is more potent than the aqueous one. Ethanol consists of both polar and nonpolar terminals at its opposite ends. Therefore it is capable of dissolving and extracting multitudes of organic compounds with a range of polarity.

Phytochemical analysis of this particular extract indicated presence of saponins, flavonoids, alkaloids, and total phenolics. Thus, the molluscicidal property of this plant is due to the availability of these bioactive phytoconstituents $[1,36]$. Saponins are important molluscicidal compounds that disrupt cellular permeability and osmoregulatory functions by interacting with membrane sterols of cells [5]. Alkaloids and terpenoids mainly act as acetylcholinesterase inhibitors resulting in neurotoxicity in snails $[30,37]$.

There are studies regarding the toxicological and pharmacological aspects of $A$. aspera. Many researches investigated no significant mammalian toxicity of the plant $[38,39]$. Rather, its antioxidant and anti-inflammatory properties due to the presence of saponins, alkaloids, and oleanolic acid $[40,41]$ are well known. On the other hand, antifertility and spermicidal properties $[42,43]$ as well as larvicidal property against Ae. aegypti [44] are indicated.

Several plants have exhibited molluscicidal activity against $B$. pfeifferi snails and related species. In the current study, the $\mathrm{LC}_{50}$ from hydroethanolic extract of $A$. aspera leaf is $20.37 \mathrm{ppm}$. It is proved to be more potent than Cymbopogon citratus where the $\mathrm{LC}_{50}$ is $159.47 \mathrm{ppm}$ [45]. It is also more potent than $G$. lotoides aqueous and ethyl acetate extracts in Kiros et al. [6] as well as Entada leptostachya and Azadirachta indica methanol extracts in Michael and colleagues [46].

The current study also showed a higher molluscicidal efficacy of $A$. aspera in the bait application as compared to the ordinary immersion method (Table 3 ). The bait application reduced the $\mathrm{LC}_{50}$ and $\mathrm{LC}_{90}$ lethal concentrations by about 6.6 and 4.2 times, respectively. The enhancement on the $\mathrm{LC}_{50}$ is greater than that on the $\mathrm{LC}_{90}$. Generally, greater efficacy enhancement was achieved in the sublethal doses than in the higher doses (Figure 1). According to previous studies, higher molluscicide titers could alter the natural taste and attractant quality of the snail food. Snails may hesitate to consume too much of it, hence reducing its palatability and effectiveness.

In line with this result, some studies have reported enhanced molluscicidal effectiveness in bait formulations [16, 17]. Nevertheless, bait effectiveness is a function of several

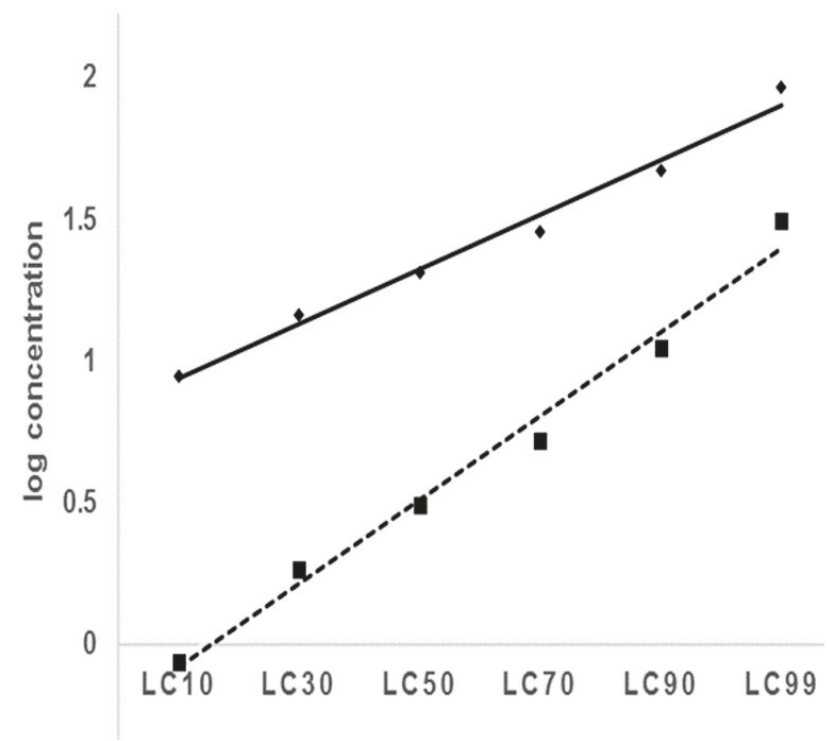

FIgURE 1: Comparative molluscicidal efficacy of $A$. aspera leaf hydroethanolic extract in bait and immersion tests against $B$. pfeiffer $i$ adult snails (broken line represents the bait test; solid line represents the immersion test).

factors such as palatability, attractant property, snail life stages, and many others $[14,17,47]$. The present study implies that alternative molluscicide applications such as baits with appropriate snail foods and attractants can be one possible mechanism to enhance the efficacy.

In immersion application, the molluscicide action is mainly by contact poisoning of the epithelial tissues in the head-foot region. Different studies reported closing of operculum, increased mucus secretion, and retracting into the shell during immersion [48]. Such protective behaviors can prevent free imbibition of molluscicidal compounds into the inner body cavities. On the other hand, molluscicidal baits act as stomach poisons [49]. Hence damage to the gastric epithelium is the main mechanism of action [14, 50, 51]. Increased efficacy in molluscicidal bait application can also be associated with other related factors. If snails avidly ingest the bioactive compounds with the food, they may accumulate in the gut to a higher local concentration at least temporarily before excretion. As the local concentration increases, greater damage is certainly expected. On the other hand, the gastric epithelium provides a larger area of poison contact than the cephalopodal surface. It may also facilitate the compounds' dispersal to hepatic tissues and other vital organs. 
Molluscicidal bait application in the control of aquatic snails has additional advantages. It prevents chemicals from direct dispersal in to the aquatic environment. Attractants in the bait lure target snails so that they ingest the molluscicide actively. On the other hand, since the bait is applied only to the snail-infested section of the water habitat, it is more economical and target specific $[16,52]$.

\section{Conclusion}

Molluscicide application in the field needs several considerations. It should be applied in lowest possible dose to minimize interference with the physicochemical properties of the aquatic habitats and adverse effects on nontarget organisms. It should also be economical for sustainable use of those valuable medicinal plants. Therefore, selection of plants with better molluscicidal efficacy and safety is mandatory. Besides, modified application techniques that enhance their effectiveness are equally important.

This study confirms the molluscicidal activity of $A$. aspera from hydroethanolic extract of the leaf part in both immersion and bait application techniques. The findings provide a strong foundation to the molluscicidal potential of this plant for community based snail control activities. Furthermore, an appreciably higher efficacy resulted from the bait test indicating possibility of its application by formulating into those commercially available snail food pellets or flakes. The research further indicated that bait applications could be one possible mechanism to enhance molluscicidal efficacy of many claimed plants as long as appropriate foods and attractants are used.

\section{Data Availability}

All data required for the analysis and conclusion are included in this article.

\section{Conflicts of Interest}

The authors declare that they have no conflicts of interest.

\section{Authors' Contributions}

Belayhun Mandefro conceived the study idea, carried out the experiment, wrote the manuscript draft, and prepared the final manuscript. Seid Tiku Mereta supervised the experiment process, organized literature search and background information, and reviewed the final manuscript. Argaw Ambelu modified the experimental design, analyzed and interpreted data, and reviewed the final manuscript.

\section{Acknowledgments}

The authors thankfully acknowledge Jimma University and Dilla University, Ethiopia, for their financial support. They got professional advices regarding the statistical model from Mr. Kibralem and the late Mr. Girma Tefera (Jimma University, Ethiopia). Mr. Yifrashewa Mengesha (Jimma University, Ethiopia) has helped in snail collection and maintenance. The authors are grateful to all of them. This work was supported by Jimma University and Dilla University, Ethiopia.

\section{References}

[1] A. A. Pereira Filho, C. R. C. França, D. D. S. Oliveira, R. J. D. A. Mendes, J. D. R. S. Gonçalves, and I. G. Rosa, "Evaluation of the molluscicidal potential of hydroalcoholic extracts of Jatropha gossypiifolia Linnaeus, 1753 on Biomphalaria glabrata (Say, 1818)," Revista do Instituto de Medicina Tropical de São Paulo, vol. 56, no. 6, pp. 505-510, 2014.

[2] P. M. Z. Coelho and R. L. Caldeira, "Critical analysis of molluscicide application in schistosomiasis control programs in Brazil," Infectious Diseases of Poverty, vol. 5, no. 1, article no. 57, 2016.

[3] D. Rollinson, S. Knopp, S. Levitz et al., "Time to set the agenda for schistosomiasis elimination," Acta Tropica, vol. 128, no. 2, pp. 423-440, 2013

[4] V. O. Adetunji and O. T. Salawu, "Efficacy of ethanolic leaf extracts of Carica papaya and Terminalia catappa as molluscicides against the snail intermediate hosts of schistosomiasis," Journal of Medicinal Plants Research, vol. 4, no. 22, pp. 23482352, 2010.

[5] G. El Sherbini, R. Zayed, and E. El Sherbini, "Molluscicidal Activity of Some Solanum Species Extracts against the Snail Biomphalaria alexandrina," Planta Medica, vol. 77, no. 12, 2011.

[6] G. Kiros, B. Erko, M. Giday, and Y. Mekonnen, "Laboratory assessment of molluscicidal and cercariacidal effects of Glinus lotoides fruits," BMC Research Notes, vol. 7, article 220, 2014.

[7] C. Yang, M. Zhang, B. Lei et al., "Active saponins from root of Pueraria peduncularis (Grah. ex Benth.) Benth. and their molluscicidal effects on Pomacea canaliculata," Pest Management Science, vol. 73, no. 6, pp. 1143-1147, 2017.

[8] F. Hanif and D. K. Singh, "Binary combination of Carica papaya, Areca catechu and Myristica fragrans with piperonyl butoxide/ MGK-264 against freshwater snail Lymnaea acuminata," Tropical Life Sciences Research, vol. 24, no. 2, pp. 1-11, 2013.

[9] J. Shahi and A. Singh, "Effect of bioactive compounds extracted from euphorbious plants on hematological and biochemical parameters of Channa punctatus," Revista do Instituto de Medicina Tropical de São Paulo, vol. 53, no. 5, pp. 259-263, 2011.

[10] R. P. Yadav and A. Singh, "Efficacy of euphorbia hirta latex as plant derived molluscicides against freshwater snails," Revista do Instituto de Medicina Tropical de São Paulo, vol. 53, no. 2, pp. 101-106, 2011.

[11] J. Xia, Y. Yuan, X. Xu et al., "Evaluating the effect of a novel molluscicide in the endemic schistosomiasis japonica area of China," International Journal of Environmental Research and Public Health, vol. 11, no. 10, pp. 10406-10418, 2014.

[12] C. H. King, D. Bertsch, and M. Knight, "Historical Perspective: Snail Control to Prevent Schistosomiasis," PLOS Neglected Tropical Diseases, vol. 9, no. 4, p. e0003657, 2015.

[13] C. A. Edwards, N. Q. Arancon, M. Vasko-Bennett, B. Little, and A. Askar, "The relative toxicity of metaldehyde and iron phosphate-based molluscicides to earthworms," Crop Protection, vol. 28, no. 4, pp. 289-294, 2009.

[14] T. R. Smith, J. White-Mciean, K. Dickens, A. C. Howe, and A. Fox, "Efficacy of four molluscicides against the giant African Snail, Lissachatina fulica (Gastropoda: Pulmonata: Achitinidae)," Florida Entomologist, vol. 96, no. 2, pp. 396-402, 2013. 
[15] D. N. Cardoso, M. J. G. Santos, A. M. V. M. Soares, and S. Loureiro, "Molluscicide baits impair the life traits of Folsomia candida (Collembola): Possible hazard to the population level and soil function," Chemosphere, vol. 132, pp. 1-7, 2015.

[16] F. Tiwari, "Bait formulation toxicity of plant derived molluscicides in attractant food pellets against vector snail, Lymnaea acuminata," World Journal of Zoology, vol. 7, no. 1, pp. 54-59, 2012.

[17] P. Kumar, V. K. Singh, and D. K. Singh, "Reproduction of Lymnaea acuminata fed to bait containing binary combination of amino acids with molluscicide," Journal of Biology and Earth Sciences, vol. 3, no. 1, pp. B65-B71, 2013.

[18] Singh., V. K. Singh, and A. K. Srivastava, "Abiotic factors and anti-reproductive action of bait containing eugenol against Lymnaea acuminata," The Journal of Biological Sciences, vol. 2, no. 4, pp. 76-85, 2013.

[19] S. Kalayou, M. Haileselassie, G. Gebre-egziabher et al., "Invitro antimicrobial activity screening of some ethnoveterinary medicinal plants traditionally used against mastitis, wound and gastrointestinal tract complication in Tigray Region, Ethiopia," Asian Pacific Journal of Tropical Biomedicine, vol. 2, no. 7, pp. 516-522, 2012.

[20] B. Tadesse, G. Mulugeta, G. Fikadu, and A. Sultan, "Survey on ethno-veterinary medicinal plants in selected Woredas of east Wollega zone, western Ethiopia," Journal of Biology, Agriculture and Healthcare, vol. 4, no. 17, pp. 97-105, 2014.

[21] A. A. Adenusi and A. B. Odaibo, "Effects of varying concentrations of the crude aqueous and ethanolic extracts of Dalbergia sissoo plant parts on Biomphalaria pfeifferi egg masses," African Journal of Traditional, Complementary and Alternative Medicines, vol. 6, no. 2, pp. 139-149, 2009.

[22] J. Kwon, G. Lee, J. M. Belanger, and J. R. Jocelyn Pare, "Effect of ethanol concentration on the efficiency of extraction of ginseng saponins when using a microwave-assisted process (MAPtm)," International Journal of Food Science \& Technology, vol. 38, no. 5, pp. 615-622, 2003.

[23] B. Sultana, F. Anwar, and M. Ashraf, "Effect of extraction solvent/technique on the antioxidant activity of selected medicinal plant extracts," Molecules, vol. 14, no. 6, pp. 2167-2180, 2009.

[24] K. J. N. Ndamukong, N. N. Ntonifor, J. Mbuh, A. F. Atemnkeng, and M. T. Akam, "Molluscicidal activity of some cameroonian plants on Bulinus species," East African Medical Journal, vol. 83, no. 3, pp. 102-109, 2006.

[25] K. O. Akinyemi, O. Oladapo, C. E. Okwara, C. C. Ibe, and K. A. Fasure, "Screening of crude extracts of six medicinal plants used in South-West Nigerian unorthodox medicine for anti-methicillin resistant Staphylococcus aureus activity," BMC Complementary and Alternative Medicine, vol. 5, article 6, 2005.

[26] S. Sasidharan, Y. Chen, D. Saravanan, K. Sundram, and L. Latha, "Extraction, Isolation And Characterization Of Bioactive Compounds From Plants' Extracts," African Journal of Traditional, Complementary and Alternative Medicines, vol. 8, no. 1, 2010.

[27] C. Mungenge, C. Zimudzi, M. Zimba, and T. Nhiwatiwa, "Phytochemical screening, cytotoxicity and insecticidal activity of the fish poison plant Synaptolepis alternifolia Oliv. (Thymelaeaceae)," Journal of Porphyrins and Phthalocyanines, vol. 2, no. 5, pp. 15-19, 2014.

[28] American Psychological Association (APA), Guidelines for ethical conduct in the care and use of nonhuman animals in research, Committee on Animal Research and Ethics (CARE), Washington DC, 2018.
[29] National Institutes of Health (NIH), PHS policy on humane care and use of laboratory animals, National Institutes of Health (NIH) Bethesda, Maryland, 2015.

[30] M. M. Salama, E. E. Taher, and M. M. El-Bahy, "Molluscicidal and mosquitocidal activities of the essential oils of thymus capitatus Hoff. ET link. and marrubium vulgare L," Revista do Instituto de Medicina Tropical de São Paulo, vol. 54, no. 5, pp. 281-286, 2012.

[31] R. Laskowski and S. P. Hopkin, "Effect of $\mathrm{Zn}, \mathrm{Cu}, \mathrm{Pb}$, and Cd on fitness in snails (Helix aspersa)," Ecotoxicology and Environmental Safety, vol. 34, no. 1, pp. 59-69, 1996.

[32] C. Weber, "Acute Toxicity Data Analysis," in Methods for measuring the acute toxicity of effluents and receiving waters to freshwater and marine organisms, pp. 66-77, Environmental Monitoring Systems Laboratory, Office of Research and Development, US Environmental Protection Agency, Cincinnati, Ohio, 4th edition, 1991.

[33] G. Otieno, G. A. Waititu, and D. Salifu, "Generalized Estimating Equations for Repeated Measures Logistic Regression in Mosquito Dose-Response," Open Journal of Statistics, vol. 03, no. 05, pp. 293-298, 2013.

[34] B. Mandefro, S. T. Mereta, Y. Tariku, and A. Ambelu, "Molluscicidal effect of Achyranthes aspera L. (Amaranthaceae) aqueous extract on adult snails of Biomphalaria pfeifferi and Lymnaea natalensis," Infectious Diseases of Poverty, vol. 6, no. 1, 2017.

[35] A. El-Din, K. El-Sayed, and M. Mahmoud, "Effect of ethanolic extract of Dalbergia sissoo plant parts on Biomphalaria alexandrina snail, the intermediate host of Schistosoma mansoni," Journal of Evolutionary Biology Research, vol. 3, no. 7, pp. 95100, 2011.

[36] H. Hammami, R. Mezghani-Jarraya, M. Damak, and A. Ayadi, "Molluscicidal activity of various solvent extracts from Solanum Nigrum Var. Villosum L. Aerial parts against Galba Truncatula," Parasite, vol. 18, no. 1, pp. 63-70, 2011.

[37] S. K. Singh, R. P. Yadav, and A. Singh, "Molluscicides from some common medicinal plants of eastern Uttar Pradesh, India," Journal of Applied Toxicology, vol. 30, no. 1, pp. 1-7, 2010.

[38] C. Reddy and A. Kamble, "Toxicity study of Achyranthus aspera," International letters of natural sciences, vol. 14, pp. 8596, 2014.

[39] A. Habtamu and Y. Mekonnen, "Evaluation of the antibacterial activities of leaf extracts of Achyranthus aspera," African Journal of Bacteriology Research, vol. 9, no. 2, p. 14, 2017.

[40] C. Priya, G. Kumar, L. Karthik, and K. Bhaskara Rao, "Phytochemical composition and in vitro antioxidant activity of Achyranthes aspera Linn (Amaranthaceae) leaf extracts," Journal of Agricultural Science and Technology, vol. 8, no. 1, pp. 143156, 2012.

[41] P. S. Kothavade, V. D. Bulani, D. M. Nagmoti, P. S. Deshpande, N. B. Gawali, and A. R. Juvekar, "Therapeutic effect of saponin rich fraction of Achyranthes aspera Linn. on adjuvant-induced arthritis in sprague-dawley rats," Autoimmune Diseases, vol. 2015, 2015.

[42] A. Dey, "Achyranthes aspera L: phytochemical and pharmacological aspects," International Journal of Pharmaceutical Sciences Review and Research, vol. 9, no. 2, 2011.

[43] R. B. Desi Reddy, P. Narisi Reddy, N. Prathibha, T. Madhu Mounica, A. Phanikumar, and M. Ravindra, "Pharmacognostic, preliminary phyto chemical and pharmacological studies on the roots of achyranthes aspera," International Journal of Pharmacognosy and Phytochemical Research, vol. 4, no. 3, pp. 139-141, 2012. 
[44] A. Sharma, S. Kumar, and P. Tripathi, "Impact of Achyranthes aspera leaf and stem extracts on the survival, morphology and behaviour of an Indian strain of dengue vector, Aedes aegypti 1. (diptera: culicidae)," Journal of Mosquito Research, vol. 5, no. 7, pp. 1-9, 2015.

[45] B. Otarigho and O. A. Morenikeji, "Molluscicidal effects of aqueous and ethanolic extracts of Lemongrass (Cymbopogon citratus) leaf against the different developmental stages of Biomphalaria pfeifferi," New York Science Journal, vol. 5, no. 8, pp. 70-77, 2012.

[46] E. Michael, D. Yole, M. Musila, H. Kutima, and P. Kareru, "Assessment of molluscicidal, cercericidal and miracicidal activities of crude extracts of Azadirachta indica and Entada leptostachya," Journal of Biology, Agriculture and Healthcare, vol. 3, no. 5, pp. 11-17, 2013.

[47] N. B. Bourne, G. W. Jones, and I. D. Bowen, "Feeding behaviour and mortality of the slug, Deroceras reticulatum in relation to control with molluscicidal baits containing various combinations of metaldehyde with methiocarb," Annals of Applied Biology, vol. 117, no. 2, pp. 455-468, 1990.

[48] S. Kamble and N. Kamble, "Behavioural changes in freshwater snail Bellamya bengalensis due to acute toxicity of copper sulphate and Acacia sinuata," International Journal of Environmental Science and Technology, vol. 3, no. 3, pp. 1090-1104, 2014.

[49] C. Salvio, A. J. Faberi, A. N. López, P. L. Manetti, and N. L. Clemente, "The efficacy of three metaldehyde pellets marketed in Argentina, on the control of Deroceras reticulatum (Müller) (Pulmonata: Stylommatophora)," Spanish Journal of Agricultural Research, vol. 6, no. 1, pp. 70-77, 2008.

[50] I. E. Ebenso, "Molluscicidal effects of neem (Azadirachta indica) extracts on edible tropical land snails," Pest Management Science, vol. 60, no. 2, pp. 178-182, 2004.

[51] D. González-Cruz and R. San Martín, "Molluscicidal effects of saponin-rich plant extracts on the grey field slug," Ciencia $e$ Investigación Agraria, vol. 40, no. 2, pp. 341-349, 2013.

[52] P. Kumar, V. K. Singh, and D. K. Singh, "Attractant food pellets containing molluscicides against the fresh water snail Indoplanorbis exustus," Global Veterinaria, vol. 8, no. 2, pp. 105110, 2012. 


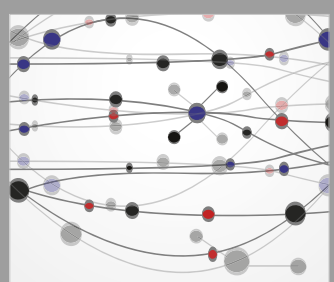

The Scientific World Journal
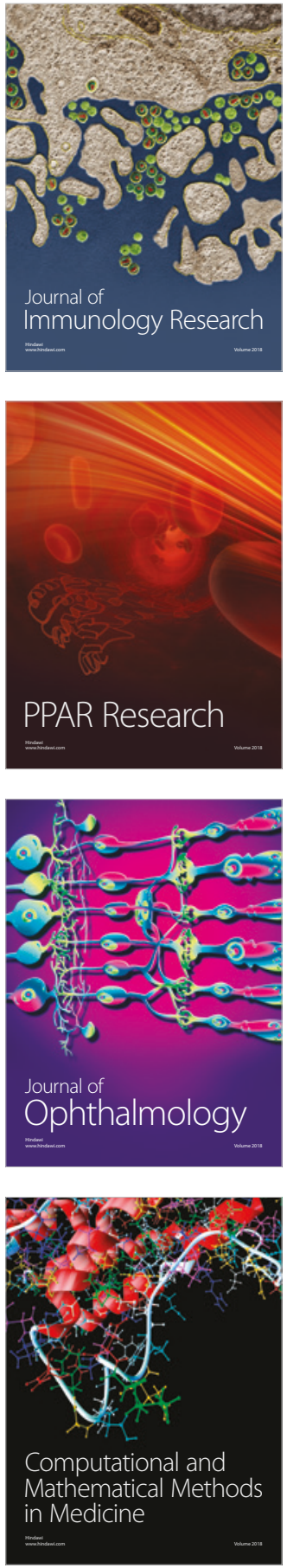

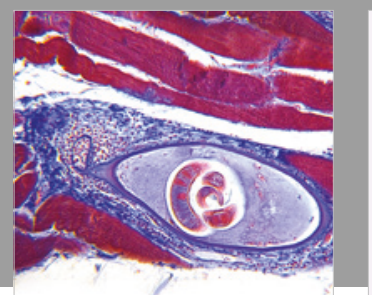

Gastroenterology Research and Practice

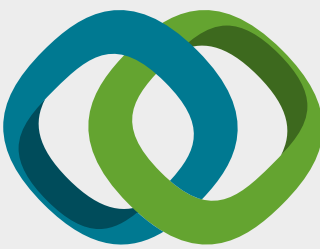

\section{Hindawi}

Submit your manuscripts at

www.hindawi.com
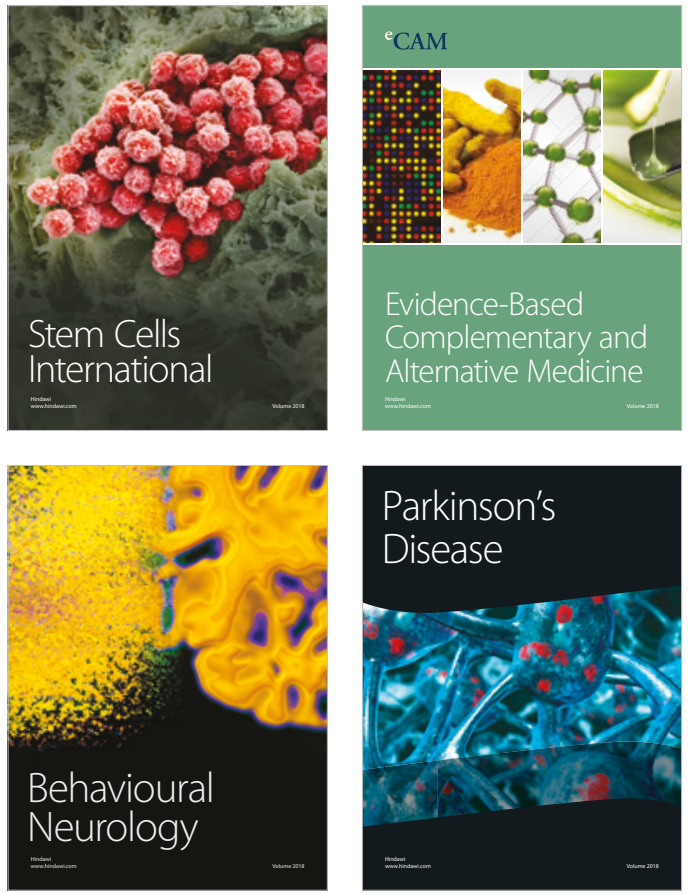

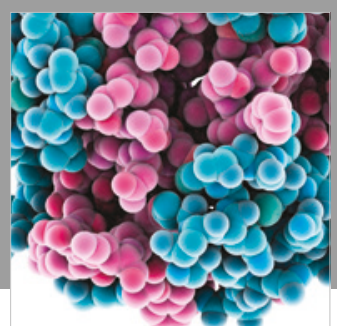

ournal of

Diabetes Research

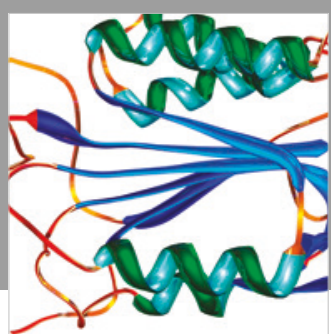

Disease Markers
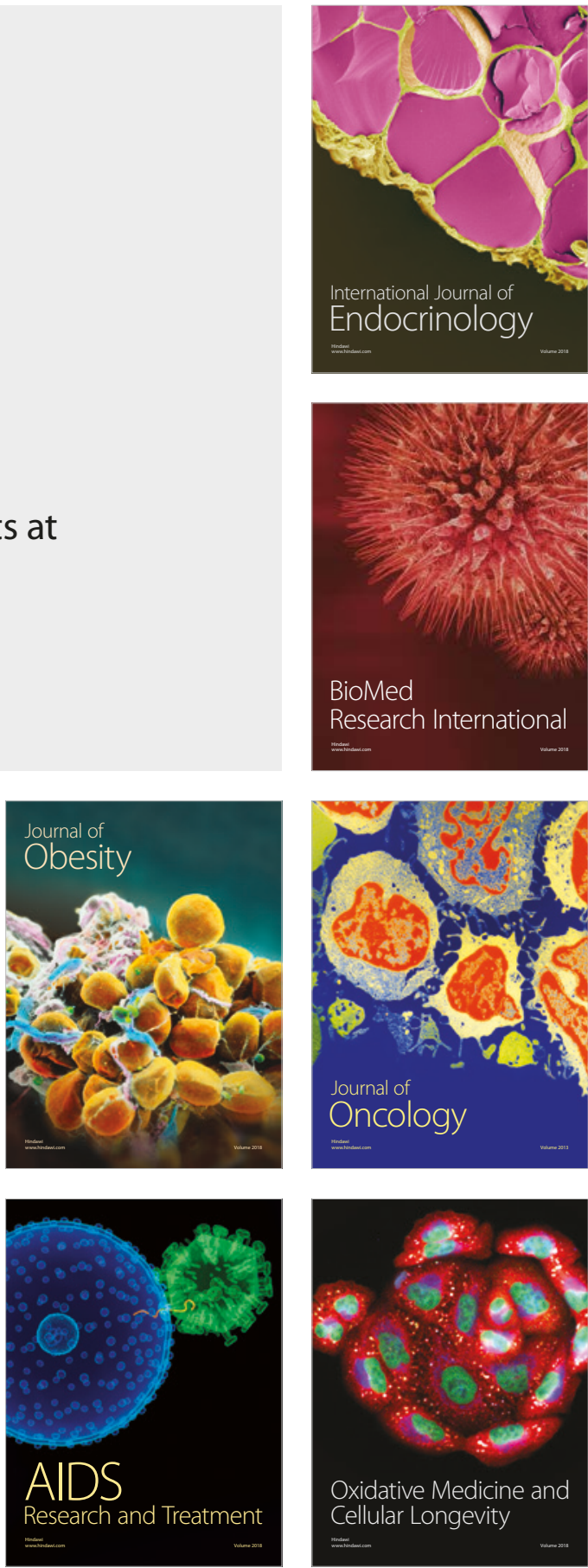